Original Research Paper

\title{
There is Life on Mars?
}

\author{
${ }^{1}$ Relly Victoria Virgil Petrescu, ${ }^{2}$ Raffaella Aversa, \\ ${ }^{2}$ Antonio Apicella, ${ }^{3}$ Samuel Kozaitis, \\ ${ }^{4}$ Taher Abu-Lebdeh and ${ }^{1}$ Florian Ion Tiberiu Petrescu \\ ${ }^{\text {I} A R o T M M-I F T o M M, ~ B u c h a r e s t ~ P o l y t e c h n i c ~ U n i v e r s i t y, ~ B u c h a r e s t, ~(C E), ~ R o m a n i a ~}$ \\ ${ }^{2}$ Advanced Material Lab, Department of Architecture and Industrial Design, \\ Second University of Naples, 81031 Aversa (CE), Italy \\ ${ }^{3}$ Florida Institute of Technology, USA \\ ${ }^{4}$ North Carolina A and T State University, USA
}

Article history

Received: 26-11-2017

Revised: 13-12-2017

Accepted: 23-12-2017

Corresponding Author: Florian Ion Tiberiu Petrescu ARoTMM-IFToMM, Bucharest Polytechnic University, Bucharest, (CE), Romania

Email: scipub02@gmail.com
Abstract: If you can live on Mars, or if there was life on this planet, it's a natural question. The population of our planet has far outstripped the boundaries from which the planet begins to overcrow. Global resources are decreasing, while their consumption is rising more and more. The world's population is growing, it needs housing, food, water, air, clothes, transport, energy and the possibilities offered by our planet are getting smaller. Because we have long been behind the "conquering space" chapter, we are now seriously thinking about limiting the existing resources for the current and future population and those who are looking for extensions on water or in desert areas. In order to conquer the cosmic space with the current technologies, it is necessary a very large financial, sustained financial effort, but unfortunately, it is not at the level of necessity. Under these circumstances, it is natural to wonder whether there is a possibility of living on Mars, which is a subject of particular interest for astrobiology due to the proximity of the planet and its similarities to the Earth. So far, no concrete evidence of past or present life has been found on Mars, but the evidence now shows clearly that during the Noachian Ancient Period, Mars' surface environment had liquid water and could be useful to microorganisms. Surely the existence of living conditions does not necessarily imply the presence of life. ExoMars (Mars Exobiology) is a two-part astrobiology project to look for Martian life proofs, a joint mission of the European Space Agency (ESA) and the Rosice Rosice Space Agency. The first part of the project, launched in 2016, placed a research and communication satellite on Marte's orbit and launched a stationary experimental landing vehicle (which collapsed). The second part of the project is planned for 2020 when a rover will be launched and landed on the surface of Mars, sustaining a scientific mission that is expected to last until 2022 or even later. The major goals of ExoMars programs are to look for previous life signs on Mars, to investigate how martian waters and geochemical environments, atmospheric gas studies and their sources vary. It will search for old biosigns in Martian life, using several elements of spacecraft that will be sent to Mars in two launches. ExoMars Trace Gas Examiners (TGO) and a stationary testator named Schiaparelli were launched on March 14, 2016. TGO entered Mars orbit on October 19, 2016 and will continue to capture methane $(\mathrm{CH} 4)$ and other gas pathways present in the Martian Atmosphere that could be a proof of possible biological or geological activity.

Keywords: Live on Mars, Martian Atmosphere, Existing Resources, Space Agency, ExoMars Programs, Biosigns in Martian Life, Atmospheric Gas, European Space Agency (ESA) 


\section{Introduction}

If you can live on Mars, or if there was life on this planet, it's a natural question. The population of our planet has far outstripped the boundaries from which the planet begins to overcrow. Global resources are decreasing, while their consumption is rising more and more. The world's population is growing, it needs housing, food, water, air, clothes, transport, energy and the possibilities offered by our planet are getting smaller. Because we have long been behind the "conquering space" chapter, we are now seriously thinking about limiting the existing resources for the current and future population and those who are looking for extensions on water or in desert areas (Aversa et al., 2017e). In order to conquer the cosmic space with the current technologies, it is necessary a very large financial, sustained financial effort, but unfortunately, it is not at the level of necessity. Under these circumstances, it is natural to wonder whether there is a possibility of living on Mars, which is a subject of particular interest for astrobiology due to the proximity of the planet and its similarities to the Earth. So far, no concrete evidence of past or present life has been found on Mars, but the evidence now shows clearly that during the Noachian Ancient Period, Mars' surface environment had liquid water and could be useful to microorganisms. Surely the existence of living conditions does not necessarily imply the presence of life.

Scientific inquiries on the evidence of life began in the nineteenth century and continue today through telescopic investigations and landings. If early studies have focused on phenomenology and have been limited to fantasy, the modern scientific inquiry has highlighted the search for water, soil biosignatures and surface rock and biomarker gases in the atmosphere. On November 22,2016 , NASA reported that it found a large amount of underground ice in the Utopia Planet area of Mars. The volume of water detected was estimated to be equivalent to the volume of water in the Upper Lake.

Mars is of particular interest in studying the origins of life because of its similarity to Early Earth. This is particularly true because Mars has a cold climate and does not have a tectonic plaque or drift mainland, so it has remained almost unchanged since the end of the Hesperian period. It can be said that at least two-thirds of Mars's surface is 3.5 billion years old and Mars can have the best data on prebiotic conditions that lead to abiogenesis, even if life does not exist or has never existed there. In May 2017, evidence of the earliest known life on earth could be found in the 3.48 billion-year geyserite and other related mineral deposits (mostly located around springs and ice) found in Craton Pilbara from Western Australia. Such recently discovered evidence could be useful to decide where to look for the best signs on Mars.

On January 24, 2014, NASA reported that Curiosity and Opportunity Martian vehicles began looking for evidence of past life, including a biosphere based on autotrophic, chemotrophic or chemolitho-ototrophic microorganisms, as well as old water (including fluvialAustralian rivers or old lakes) that could have been habitable. More recently, searching for evidence of habitats, taphonomy (fossil-related) and organic carbon on Mars is now a major objective of NASA.

In July 2017, the researchers reported that the surface of Mars could be more toxic to microorganisms, especially a common terrestrial type, Bacillus subtilis, than originally believed, the claim based on studies of perchlorates used on Mars, in a simulated Martian ultraviolet atmosphere.

On September 5, 2017, scientists reported that Curiosity rover on Mars detected boron, an essential ingredient for life on Earth. Such a discovery, along with previous discoveries of the fact that liquid water was clearly present on the ancient Mars, still support the possible adaptation of Mars to life (Life on Mars, From Wikipedia; Petrescu et al., 2017a; 2017b; 2017c; 2017d; 2017e; 2017f; 2017g; 2017h; 2017i; 2017j; 2017k; 20171; 2017m; 2017n; 2017o; 2017p; 2017q; Petrescu, 2016; Aversa et al., 2017a; 2017b; 2017c; 2017d; 2016a; 2016b; 2016c; 2016d; Mirsayar et al., 2017; Petrescu and Petrescu, 2016a; 2016b; 2016c; 2013a; 2013b; 2013c; 2013d; 2012a; 2012b; 2012c; 2012d; 2011a; 2011b; Petrescu, 2012a; 2012b; 2012c; 2009; Petrescu and Calautit, 2016a; 2016b; Petrescu et al., 2016a; 2016 b).

\section{Materials and Methods}

ExoMars (Mars Exobiology) is a two-part astrobiology project to look for Martian life proofs, a joint mission of the European Space Agency (ESA) and the Rosice Rosice Space Agency. The first part of the project, launched in 2016, placed a research and communication satellite on Marte's orbit and launched a stationary experimental landing vehicle (which collapsed). The second part of the project is planned for 2020 when a rover will be launched and landed on the surface of Mars, sustaining a scientific mission that is expected to last until 2022 or even later.

The major goals of ExoMars programs are to look for previous life signs on Mars, to investigate how martian waters and geochemical environments, atmospheric gas studies and their sources vary. It will search for old biosigns in Martian life, using several elements of spacecraft that will be sent to Mars in two launches.

ExoMars Trace Gas Examiners (TGO) and a stationary testator named Schiaparelli were launched on March 14, 2016. TGO entered Mars orbit on October 19, 2016 and will continue to capture methane $(\mathrm{CH} 4)$ and other gas pathways present in the Martian Atmosphere that could be a proof of possible biological or geological activity. TGO has four instruments and will act as a retransmission satellite of communications. The Schiaparelli experimental space was separated from 
TGO on October 16 and was maneuvered to land in Meridiani Planum, but collapsed on the surface of Mars. The landing was designed to test new key technologies to safely deliver the rover 2020 mission.

In 2020, a platform built by Roscosmos (the ExoMars 2020 platform; Fig. 1) will have to deliver an ExoMars Rover built by ESA on the Martian surface. The rover will include some tools built by Roscosmos. The two missions and communications operations will be led by Italy's Rover ALTEC Control Center (ExoMars, From Wikipedia).

Since it was first designed, the ExoMars program has gone through several planning stages, with various landing, orbiting, launching and international cooperation planning proposals, such as the Mars Exploration 2009 (MEJI) Joint Initiative with the United States. Initially, the ExoMars concept consisted only of a large robotic system that is part of ESA's Aurora program as a flagship mission and was endorsed by the Ministries of the European
Space Agency in December 2005. It was originally conceived as a rover with a stationary ground station in 2011 aboard a Russian rocket Soyuz Fregat.

In fact, we can assume that the ExoMars project started in 2001 as part of the ESA Aurora program for the human exploration of Mars. This initial vision later made a call for the rover in 2009 and later a return mission. Another mission to support the Aurora program is a mission to return Phobos. In December 2005, the different ESA states approved both the Aurora program and the ExoMars project. Aurora is an optional program and each state has the right to decide which part of the program it wants to be involved and to what extent (for example, how many funds can be deposited in the program). The Aurora program was launched in 2002 with the support of twelve countries: Austria, Belgium, France, Germany, Italy, the Netherlands, Portugal, Spain, Sweden, Switzerland, the United Kingdom and Canada.

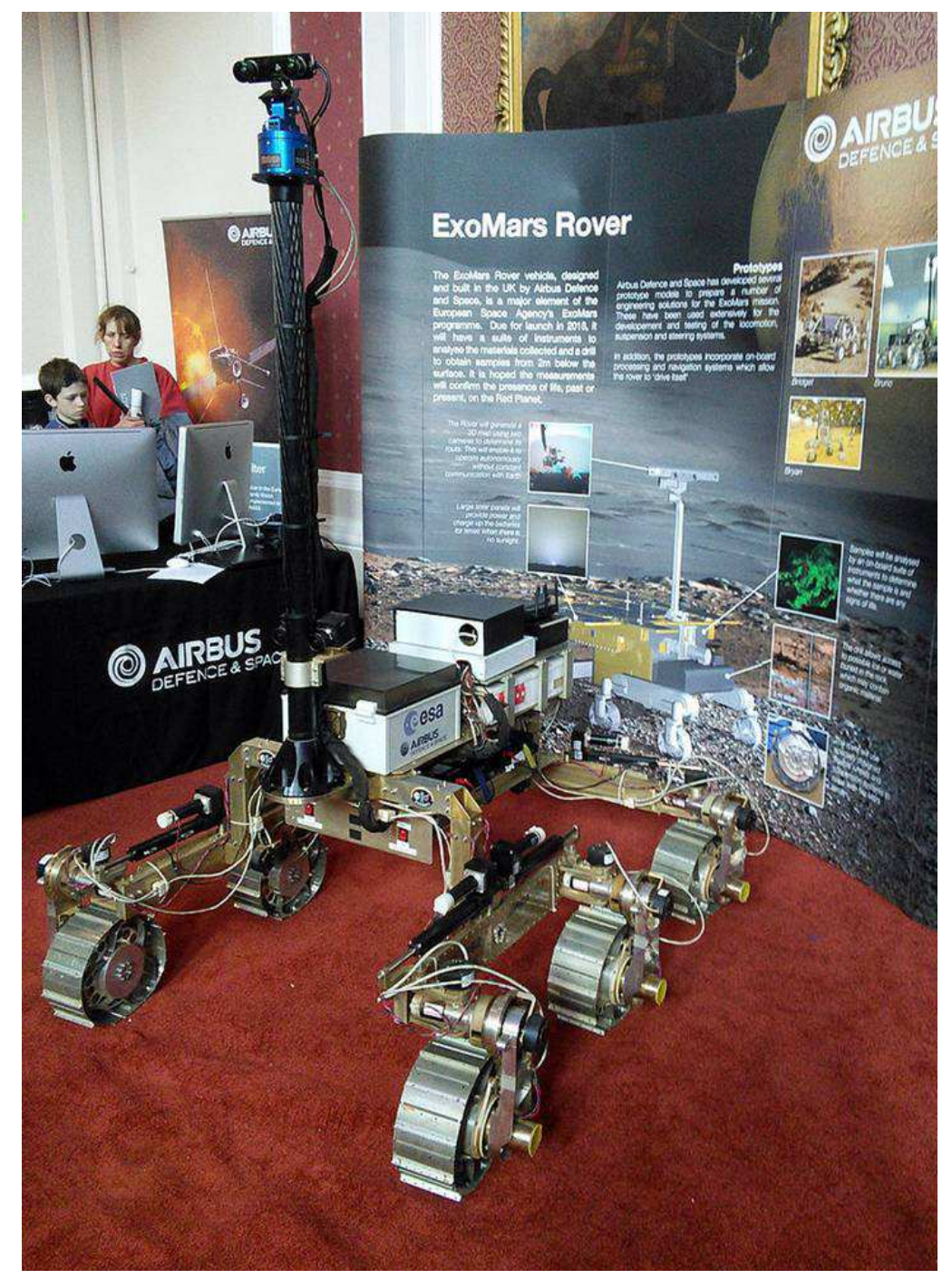

Fig. 1: A prototype of the ExoMars Rover at the 2015 Cambridge science festival 
In 2007, Macdonald Dettwiler and Associates Ltd. (MDA) was selected by a one million euro contract with EADS Astrium in the UK to design and build a prototype chassis for the Martian rotor to be used by the Space Agency EU. Astrium has also been contracted for the final design of the Martian rover.

In July 2009, NASA and ESA made a major step forward for the program by signing the Joint Exploration Mars initiative, which proposed the use of an Atlas rocket launcher instead of the Soyuz type, which significantly changed the technical settings and financials of the entire ExoMars mission. On June 19, when it was planned to release Mars Trace Gas Orbiter, it was reported that a prospective agreement called for the need for ExoMars to lose much weight in order to fit on board the Atlas launch vehicle with a NASA orbiter (Fig. 2).

In addition, the mission was combined with other projects in a multi-spatial mission divided into two Atlas V launches. On this occasion, the ExoMars Trace Gas Orbiter (TGO) was integrated into the project, carrying a stationary meteor landing ready for launch January 2016. It was proposed to include a second rover, MAX-C.

In August 2009, the Russian Federal Space Agency (Roscosmos) and ESA signed an important contract, including co-operation in two Mars exploration projects: Russia's Fobos-Grunt project and ExoMars belonging to ESA. ESA has ensured that a Proton Russian missile that will be a "reserve launcher" for the ExoMars rover would also include various components manufactured in Russia.
On December 17, 2009, all AES governments have given their final agreement to a two-pronged exploration mission on the planet Mars, a mission that will also be carried out with NASA, confirming their commitment to spend 850 million euro for missions to be carried out in 2016 and 2018

Unfortunately, even two years later, in April 2011, due to a budget crisis, a proposal to cancel the MAX-C companion rover was announced and decided to fly with only one rover in 2018, claiming it would be greater than any of the vehicles in the associated concept.

There was also a suggestion that the new vehicle will be built in Europe but will carry a mix of European and American instruments. NASA would provide missile systems capable of delivering it to Mars and providing the crane landing system.

Despite the drastic reorganization imposed, it was suggested that the objectives of the 2018 mission would remain unchanged.

A new blow will be cashed in by this important program for the future of mankind, due to the 2013 US budget prepared and approved by President Obama as early as February 13, 2012, when NASA ceased participating in ExoMars because of budget cuts to pay overpayments cost of the James Webb Space Telescope.

Now the project's situation was more than desperate, especially financially and technically and due to the total loss of US NASA funding (for this project completely canceled) and most of these plans had to be restructured again.

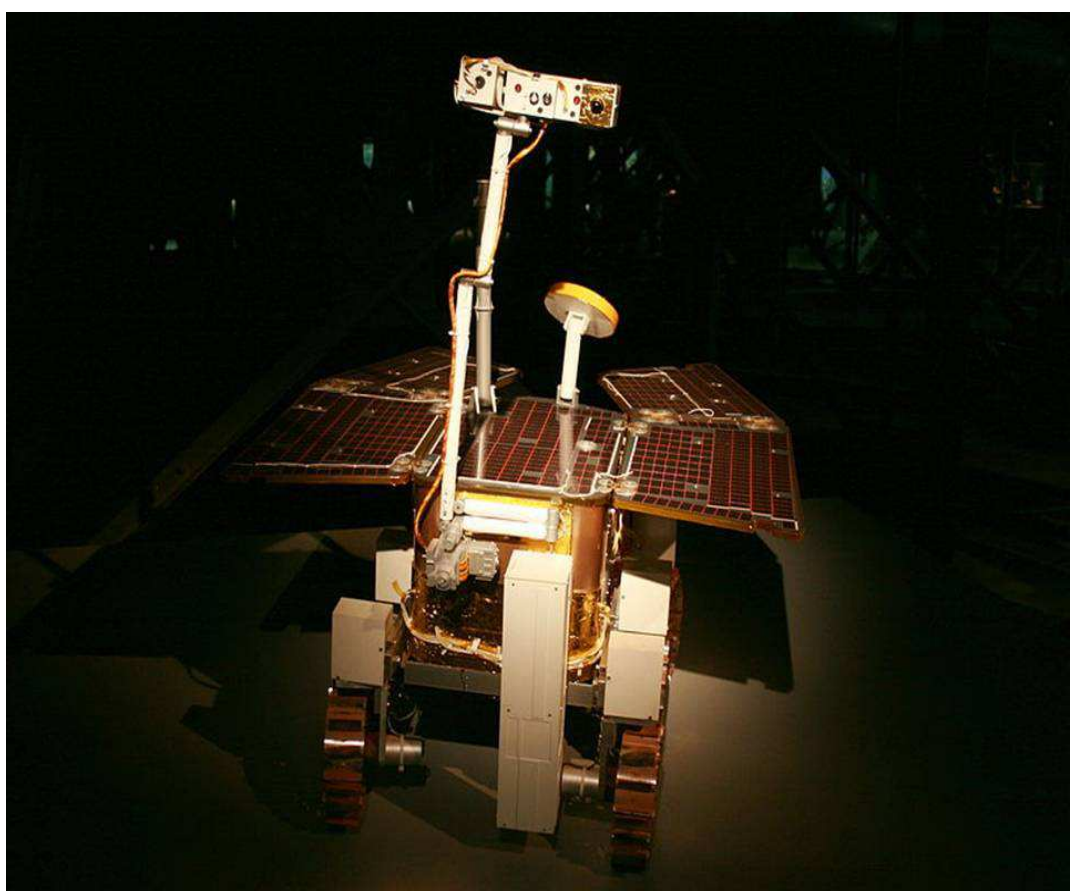

Fig. 2: An ExoMars rover as an exhibit at Gasometer Oberhausen, Germany 
For this reason, Obama's withdrawal of US and NASA support for the program on March 14, 2013, met with emergency representatives of ESA and the Russian space agency (Roscosmos) and signed an agreement by which Russia became a full partner of the project (occupying the place left empty by Obama's Americans). Roscosmos will now deliver Briton-M and launch services to Proton launch vehicles for both missions, as well as an additional entry, lowering and landing module for the rover mission in 2018. Under the new agreement, Roscosmos was granted the three required conditions:

Roscosmos will contribute two Proton vehicle launchers as a partnership payment.

Trace Gas Traffic Orbiter will include two Russian instruments that were originally developed for Phobos-Grunt.

All scientific results must be the intellectual property of the European Space Agency and the Russian Academy of Sciences (that is, Roscosmos will have full access to research data).

\section{Results}

ESA initially estimated ExoMars projects at about 1 billion euros (The US $\$ 1.3$ billion), but with the withdrawal of the US space agency (NASA) in the 2012-2013 project and the subsequent reorganization of associations will probably add several hundred million euros.

Thus, the Member States instructed the Agency's Director to analyze how this deficit could be achieved. One possibility is that other scientific activities within the ESA will be closed, modified, postponed so that the funds originally allocated to them go to the ExoMars project to make ExoMars a priority. Since September 2012 it has been announced that part of the additional amount will be covered by attracting new members within the project and the new members already proposed, Poland and Romania, will contribute 70 million euros for the ExoMars mission.

As a last reservation on the important ExoMars project, ESA did not exclude the possibility of the US and NASA returning to the program as a full or partial partner somewhere until 2018 if America's policy changes again with the change of leadership. This possibility is not yet certain, funding from it has been considered as a supplement and additional help.

ExoMars funding by Russia could be partly covered by insurance payments of 1.2 billion rubles $(\$ 40.7$ million) for Phobos-Grunt's loss and reallocation of funds for eventual coordination between Mars-NET projects and ExoMars.

On January 25, 2013, Roscosmos fully funded the development of the scientific tools to be launched at the first launch, Trace Gas Orbiter (TGO).

Beginning in March 2014, ExoMars, the British division of Airbus Defense and Space, began to acquire critical components, but the 2018 mission was still frustrated by more than 100 million or $\$ 138$ million in terms of where Canada has also offered to support the project (Wheel and Suspension System are paid by the Canadian Space Agency and are manufactured by MDA Corporation in Canada).

Although it was obvious that the loss of US support was great for the project and even destroying it, this important project for mankind was saved by Europe, Russia, England and Canada, who managed to take the huge shock of America's breakaway, at the express request of the then president, Obama. It sometimes happens that one man will change the fate of mankind for good or evil, but even if it is now the loss of an essential project for humanity through the intervention of a single man, Obama, here is the combined support of Great Britain, Europe, Russia and Canada, saved the project on time.

What followed: Spaceship ExoMars Trace Gas Orbiter containing (TGO) and Schiaparelli was launched on March 14, 2016 (Livestream started at 08:30 GMT [3:30 AM EDT]). Four rocket stages took place within the next $10 \mathrm{~h}$ before the descent module and the orbiter could be released. Thus the signal from Orbiter was successfully received at 21:29 GMT of the same day, which confirmed that the launch was successful and that the space ship is heading to Mars. Shortly after the probe separation, the Briz-M upper support step exploded a few kilometers away, apparently without damaging the orbit or soil. The spacecraft, which hosted Trace Gas Orbiter and the Schiaparelli land, took their nominal orbit to Mars and seemed to be in operation. Over the next two weeks, the controllers continued to verify and make available their systems, including propulsion systems, communications, star tracking and navigation and guidance.

\section{Discussion}

Recent models have shown that even with a dense atmosphere of $\mathrm{CO}^{2}$ in early March it was colder than it ever was on Earth. It is believed that temporary heatrelated conditions of impact or volcanism could have created favorable conditions for network formation of the late noachi valley, even if the midday weather of the nobles were probably frozen. Although it seems that the local warming of the environment through volcanism and impact would have been sporadic, yet there would have been many water events flowing to the surface of Mars. So both mineralogical and morphological evidence clearly and clearly indicate that a degradation of the Hesperian mid-habitats took place on Mars. The exact causes are not yet well understood but can be correlated with a combination of processes, including early atmospheric loss or impact erosion, or both. 
Basically, what really supports life on Tera is primarily the Earth's magnetic field, which then supports all the other defenses of our planet. The loss of the Martian magnetic field has obviously influenced surface environments through atmospheric losses and increased radiation; this change significantly degraded the surface habitats. As long as there was a magnetic field, the atmosphere on Mars would have been protected from solar wind erosion, which would ensure the maintenance of a dense atmosphere necessary for the existence of liquid water on the surface of Mars. By losing the magnetic field and then the Martian atmosphere, all the living conditions on the planet have been degraded. The loss of the atmosphere was accompanied by lower temperatures. Some of the liquid water inventory was sublimated and transported to the poles, while the rest was caught in permafrost, an underground layer of ice. Another part of the water and the atmosphere turned or lost. Obviously, through the study of what happened on Mars, we can find other data on the degradation of living conditions on any planet, with the loss of its magnetic field, followed by the loss of its atmosphere.

Observations on Earth and numerical modeling have shown that a crater formation impact can result in the creation of a long-lasting hydrothermal system when the ice is present in the crust. For example, a $130 \mathrm{~km}$ long crater could sustain an active hydrothermal system of up to 2 million years, that is long enough for microscopic life to occur (Fig. 3); Alga crater is thought to have deposits of impact glass that may have preserved ancient biosignatures if present during the impact.
Soil and stone samples that were explored in 2013 by NASA vessel Curiosity tools have brought extra critical extra information about several habitats.

The Rover team has identified some of the main chemical ingredients for life in this soil, including sulfur, nitrogen, hydrogen, oxygen, phosphorus and possibly carbon, as well as clay minerals, which suggests the existence of a long-lasting aqueous medium - or an old river - which was neutral and not too salty.

On December 9, 2013, NASA reported that, based on the Curiosity evidence that studied Aeolis Palus, Gale Crater contained an old freshwater lake that could have been a very hospitable environment for microbial life. This has confirmed that water flowed on Mars, that there were nutrients and, together with the earlier discovery of a past magnetic field that protects the planet from cosmic and solar radiation, suggests that Mars could have environmental factors that would sustain life.

However, the evaluation of past habitats is not in itself a proof that Martian life has ever existed, but only that it could exist. If it did, it was probably microbial, either in fluid or sediment, either freely or possibly biofilm.

The possibility of life on the planet Mars is a historical hypothesis formulated because of the proximity and similarities between this planet and the Earth. The first serious investigations on this subject date back to the nineteenth century and are continuing today, particularly with the help of in situ exploration missions. Because, although "Martians" are a recurring element in popular entertainment such as film and comics, the presence of life on Mars, past or present, remains an open question.

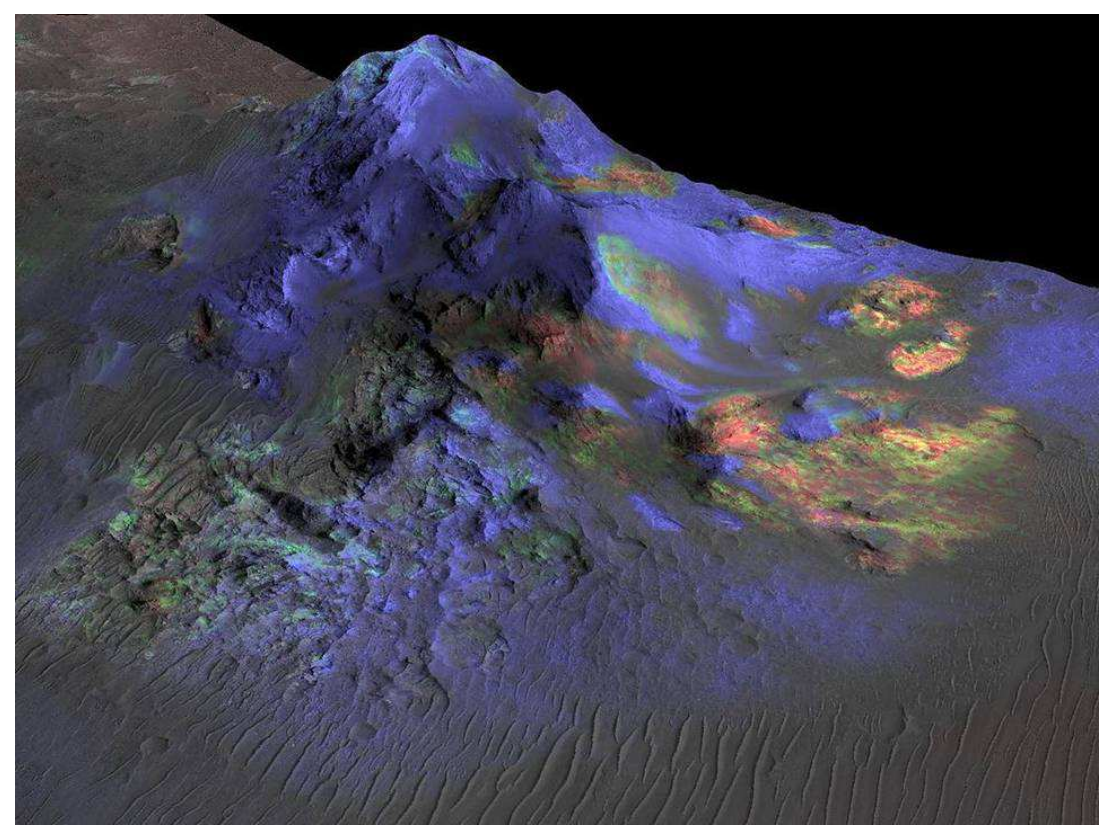

Fig. 3: Alga crater is thought to have deposits of impact glass that may have preserved ancient biosignatures if present during the impact 
If the first observation of the Martian polar ice caps dates from the middle of the 17th century, it is during the second half of the 18th century that William Herschel notes the alternative variation of their area on each hemisphere according to the seasons.

Around 1850, astronomers highlighted some similarities between Mars and Earth. The duration of the day is in fact essentially the same on both planets, as is the inclination of the axis of rotation which generates the alternation of seasons (although the Martian year is about twice as long as its terrestrial equivalent). These observations lead to the hypothesis that the dark areas visible on Mars correspond to oceans, while the lighter areas are continents. It is natural then to assume that Mars can house some life forms. William Whewell, a professor at Trinity College at Cambridge University, explains this theory in 1854 .

Theories concerning life on Mars multiplied at the end of the nineteenth century, following the observations of Martian channels - which finally turned out to be mere optical illusions. Thus, in 1895, the American astronomer Percival Lowell publishes his book Mars, followed in 1906 by Mars and its channels, in which he proposes the idea that these channels are the fruit of a civilization long since disappeared. This theory is particularly taken up by the British writer $\mathrm{H}$. G. Wells in his book The War of the Worlds (1887), which describes an invasion of the Earth by beings from Mars and fleeing its desiccation.

Spectroscopic analyzes of the Mars atmosphere begin in 1884. The American astronomer William Wallace Campbell shows that it contains neither oxygen nor water 2. In 1909, taking advantage of the shortest distance between Mars and Earth since 1877, astronomers point the best telescopes in the world on the red planet. These observations make it possible to definitively end the channel theory.

In 1965, the American spacecraft Mariner 4 is the first to successfully fly over Mars, transmitting the first images of its surface. The photographs reveal an arid planet without any sign of river, ocean, or life. However, they show large areas covered with craters, reflecting tectonic and meteorological inactivity for about four million years.

The probe also notes the absence of a magnetosphere that would have protected the planet from cosmic rays hostile to life. It manages to measure the atmospheric pressure of Mars: About $6 \mathrm{hPa}$ (against $1013 \mathrm{hPa}$ on Earth), which prohibits the existence of liquid water on the surface.

Since Mariner 4, the search for life on Mars has focused on finding simple living organisms, similar to bacteria, rather than multicellular organisms, for which the environment is too hostile.

In the mid-1970s, the main goal of the Viking program was to conduct microorganism detection experiments in Martian soil. The tests are designed to look for life forms similar to those found on Earth. Of the four experiments implemented, only the "Labeled Release" experiment (corresponding to the detection of heterotrophic organisms) provides an apparently positive result, showing an increase in ${ }^{14} \mathrm{CO}_{2}$ production at the first exposure of Martian soil to a medium rich in water and nutrients. But scientists today agree that these results are the result of non-biological processes and recall that the "GC-MS" experiment did not detect any organic molecule. Nevertheless, many different interpretations still exist as to these experiences.

One of the designers of "Labeled Release", Gilbert Levin, thinks that his results are a definitive diagnosis of life on Mars. However, this is disputed by many scientists, who claim that superoxidant species present in the soil may have produced these effects without any presence of life. An almost general consensus has therefore rejected the data from the LR experiment as a proof of life, because gas chromatographs and mass spectrometers, aimed at identifying natural organic matter, have not made it possible to detect molecules. organic. The results of the Viking mission concerning life are therefore considered by the majority of experts at best as inconclusive, at worst as invalid.

In 2007, at a seminar of the Geophysical Laboratory of the Carnegie Institution in Washington, the Gilbert Levin experiment was evaluated once again. Levin still claims that his original data is correct.

Ronald Paepe, an edaphologist (soil scientist), said at the European Geoscience Congress that the recent detection of phyllosilicate clays on Mars could result from pedogenesis spread over the entire surface of the planet. Paepe's interpretation sees the surface of Mars as an active soil colored red by eons of erosion, caused by water, vegetation and microbial activity.

A team of researchers from the National Autonomous University of Mexico, led by Rafael Navarro-Gonzalez, has concluded that the material used (TV-GC-MS) by the Viking program to search for organic molecules may not be enough sensitive to detect low levels of organic compounds. Due to the simplicity of sample handling, TV-GC-MS is still considered the standard method of organic detection for future Martian missions. NavarroGonzález suggests that the design of future organic matter search instruments on Mars incorporates other detection methods.

The affirmation of the existence of life on Mars, in a microbial form called Gillevinia straata, is based on old data reinterpreted as sufficient proof of life, mainly by professors Gilbert Levin, Rafael Navarro-Gonzalez and Ronald Paepe. The evidence supporting the existence of Gillevinia straata microorganisms is based on data collected by the two Viking undercarriages, designed for biosignature research. However, the analytical results have been officially declared inconclusive by the scientific community. 
In 2006, Mario Crocco, a neurobiologist at the Borda Neuropsychiatric Hospital in Buenos Aires, Argentina, proposed the creation of a new taxon classifying these results as "metabolic" and therefore belonging to a life form. Such categories would be able to accommodate this kind of Martian microorganisms in the living kingdom. Crocco proposes the following entry:

- System of organic life: Solaria

- Biosphere: Marciana

- Reign: Jakobia (named after neurobiologist Christfried Jakob)

- Genus and species: Gillevinia straata

As a result, Gillevinia straata is not a bacterium (which is rather an earth taxon), but a member of the "Jakobia" reign of the "Marciana" biosphere of the "Solaria" system.

The intended effect of the new nomenclature was to reverse the burden of proof on the issue of life, but the taxonomy proposed by Crocco has not been accepted by the scientific community and is considered a mere nomen nudum. In addition, no other Martian mission has found traces of biomolecules. The affirmation of the existence of life on Mars, in a microbial form called Gillevinia straata, is based on old data reinterpreted as sufficient proof of life, mainly by professors Gilbert Levin, Rafael Navarro-Gonzalez and Ronald Paepe. The evidence supporting the existence of Gillevinia straata microorganisms is based on data collected by the two Viking undercarriages, designed for biosignature research. However, the analytical results have been officially declared inconclusive by the scientific community.

In 2006, Mario Crocco, a neurobiologist at the Borda Neuropsychiatric Hospital in Buenos Aires, Argentina, proposed the creation of a new taxon classifying these results as "metabolic" and therefore belonging to a life form. Such categories would be able to accommodate this kind of Martian microorganisms in the living kingdom. Crocco proposes the following entry:

- $\quad$ System of organic life: Solaria

- Biosphere: Marciana

- Reign: Jakobia (named after neurobiologist Christfried Jakob)

- Genus and species: Gillevinia straata

As a result, Gillevinia straata is not a bacterium (which is rather an earth taxon), but a member of the "Jakobia" reign of the "Marciana" biosphere of the "Solaria" system.

The intended effect of the new nomenclature was to reverse the burden of proof on the issue of life, but the taxonomy proposed by Crocco has not been accepted by the scientific community and is considered a mere nomen nudum. In addition, no other Martian mission has found traces of biomolecules.

The analysis of meteorites to prove an (old) life on Mars is controversial, but of great interest to biologists. The very existence of a unicellular life in March would corroborate theories of the origin of life. NASA has a collection of at least 57 Martian meteorites, which are extremely useful in that they are the only physically available samples from Mars.

Speculation has increased when studies have shown that at least three of them have evidence of potential life on Mars in the past. Although the scientific results are reliable, their interpretations vary. To date, despite numerous publications, the debate has not been resolved.

In recent decades, seven criteria have been used for the recognition of past life in terrestrial geological samples. These criteria are:

- Is the geological context of the sample compatible with past life

- Are the age of the sample and its stratigraphic location compatible with a possible life

- Does the sample contain evidence of cell morphology and colonies

- Is there evidence of biominerals showing chemical or mineral imbalances

- Is there evidence of stable isotopes unique to the biological model

- Is there the presence of organic biomarkers

- Are the features indigenous to the sample

For a general consensus on the evidence of past life in a geological sample, most or all of these criteria must be met.

The ALH84001 meteorite was found in Antarctica in December 1984 by members of the ANSMET program; the meteorite weighs $1.93 \mathrm{~kg}$.

The sample was ejected from Mars about 17 million years ago and spent 11,000 years in or on the Antarctic ice. NASA's analysis of its composition revealed a kind of magnetite that is found on Earth only in association with certain micro-organisms; then, in August 2002, another NASA team, led by Thomas-Keptra, published a study indicating that $25 \%$ of the magnetite of ALH84001 appears as small, uniform-sized crystals that, on Earth, are associated with a biological activity and that the rest of the material appears to be inorganic normal magnetite. The extraction technique does not make it possible to determine whether, possibly, biological magnetite has been organized in chains as one would expect. The meteorite shows the indication of a relatively low mineralization temperature by water and shows the traces of pre-earth aqueous alteration. Traces of Polycyclic Aromatic Hydrocarbons (PAHs) have been found at increasing levels away from the surface. 
Some structures resemble moldings of the fossilization of terrestrial bacteria and their appendages (fibrils) or byproducts (polymeric extracellular substances) on the edges of carbonate globules and preterrestrial aqueous spoilage. The size and shape of the objects are compatible with those of fossilized terrestrial nanobacteria, but the existence of nanobacteria is itself controversial.

The meteorite of Nakhla fell on the Earth on June 28, 1911, on the locality of Nakhla, Alexandria, Egypt.

In 1998, a team from NASA's Johnson Space Center obtained a small sample for analysis. The researchers found preterrestrial aqueous alterations and objects of consistent size and shape with fossilized terrestrial nanobacteria, but the existence of nanobacteria itself is controversial.

In 2000, gas chromatography and mass spectrometry (GC-MS) analysis investigated its high molecular weight polycyclic aromatic hydrocarbons; NASA researchers concluded that up to $75 \%$ of organic matter in Nakhla may not be a recent terrestrial contamination.

The Shergotty meteorite is a $4 \mathrm{~kg}$ Martian meteorite that fell to Earth in Shergotty, India on August 25, 1865 and was recovered by witnesses almost immediately.

This meteorite is relatively young, its formation was calculated only 165 million years ago, of volcanic origin. It is composed mainly of pyroxene and it is thought that it has undergone a pre-terrestrial aqueous alteration of several centuries. Some indoor formations are reminiscent of biofilm remnants and their microbial communities. Work is underway in search of magnetite with alteration phases.

No other Mars probe since Viking has looked for signs of life in the Martian regolith. Recent NASA missions have focused on the issue of the presence of liquid water on Mars, in the form of lakes, in the distant past. Indeed, scientists have found hematite, a mineral that forms in the presence of water. Many scientists have long held this presence as almost self-evident on the basis of the various geological reliefs of the planet, but others have proposed different explanations, wind erosion, oceans of oxygen, etc. Thus, the Mars Exploration Rovers mission of 2004 was not the search for present or past life, but the evidence of liquid water on the surface of Mars in the ancient past of the planet.

In June 2000, evidence of a stream beneath the surface of Mars was discovered in the form of gullies. Reserves of liquid water at great depth, near the core of the planet, could constitute today the habitat of life. However, in March 2006, astronomers announced the discovery of similar gullies on the Moon, which never seems to have had liquid water on its surface. Astronomers suggest that gullies could be the result of micrometeorite impacts or sublimation of carbon dioxide.

In March 2004, NASA announced that its robot Opportunity had discovered evidence that the Mars planet was, in the distant past, a wet planet. This has raised hopes that proof of life in the past could be found on the planet today.
In December 2006, NASA showed images taken by the Mars Global Surveyor probe that suggested that water was springing up from time to time on the surface of Mars. The images do not show dripping water. On the contrary, they showed changes in craters and sediment deposits, providing even stronger evidence that water had trickled through them no later than several years ago and could possibly to be doing it again today. Some researchers are skeptical about the action of liquid water in the evolution of the surface seen by the probe. They said that other materials such as sand or dust can flow like a liquid and produce similar results.

A recent analysis of Mars sandstone, using data obtained from orbit spectrometry, suggests that the waters that previously existed on the surface of Mars would have been too saline to support most terrestrial life forms. Tosca et al. found that Martian water in the places they studied had water activity, aw $\leq 0.78$ to 0.86 - a fatal level for most terrestrial life. Haloarchaea, however, is able to live in hypersaline solutions, to the point of saturation (Tosca et al., 2008).

The Phoenix Mars Lander of NASA, which landed in the Arctic Plain of Mars in May 2008, confirmed the presence of water ice near the surface. This was confirmed when bright materials, exposed by digging the probe arm, vaporized and disappeared in 3-4 days. This was explained by ice under the surface, exposed by digging, which sublimated by exposure to the atmosphere.

Traces of methane in the atmosphere of March were discovered in 2003 and verified in 2004. The presence of methane is very intriguing, because this gas is unstable, it indicates that there must be a source on the planet to maintain a such a rate in the atmosphere. It is estimated that Mars must produce 270 metric tons of methane a year; meteorite impacts contributed only $0.8 \%$ to this production. Geological sources of methane such as serpentinite are possible, the lack of volcanism, hydrothermal activity or hot spot is not favorable to geological methane. In 2012, cosmochemical researchers published an article in the journal Nature, observing that organic materials that can be contained in micrometeorites produce methane in a significant amount under the action of ultraviolet. This production of methane is reinforced with an increase in temperatures this corresponds to regions where precisely there is a greater concentration of methane that is to say the equatorial regions. The existence of life in the form of microorganisms such as methanogens is a possible source, but not yet proven. If there is microscopic Martian life producing methane, it probably lies deep below the surface, where it is still warm enough to allow liquid water to exist.

In February 2005, it was announced that the Planetary Fourier Spectrometer (PFS) on Mars Express Orbiter of the European Space Agency, has detected traces of formaldehyde in the atmosphere of Mars. Vittorio Formisano, the director of the PFS, speculated that formaldehyde could be the byproduct of methane oxidation 
and, according to him, to provide evidence that Mars is geologically very active, or hosts colonies of microbial life. NASA scientists viewed these preliminary results as a worthy track, but they also rejected them as proof of life.

In May 2007, the Spirit rover disrupted a parcel of land with its broken wheels, revealing an area extremely rich in silica $(90 \%)$. The characteristic is not unlike the effect of a hot spring and/or water vapor coming into contact with volcanic rocks. Scientists believe that this evidence of an environmental past may have been favorable to microbial life and their theory about the possible origin is that silica was produced by the interaction of soil with the acidic vapors produced by volcanic activity in the presence of water. Another could have been from the environment of a hot spring.

Dark dune spots, also known as martian spiders, are features that can be seen primarily in the southern polar region (between 60 and $80^{\circ}$ latitude) of Mars, on or under the polar ice cap. The spots were discovered on images taken by the Mars Global Surveyor probe in 1998-1999. The spots appear in early Martian spring and disappear before the beginning of winter.

A theory on the possible biological origin of spots has been issued by a Hungarian team, they propose that the spots are colonies of photosynthetic Martian microorganisms, which live under the ice layer. When the Sun returns to the pole in early spring, the light penetrates the ice, the micro-organisms photosynthesize it warming their immediate environment; a pocket of liquid water, which would normally evaporate instantly in the thin atmosphere of Mars, is trapped in the ice.

When the ice layer thins, the microorganisms are seen in gray. When it has completely melted, they dry out quickly and turn black, surrounded by a gray halo. The haloarchaea bacterium (en) "salt-loving" has been proposed to be used as a "model" to study these hypothetical extremophiles of Mars.

NASA's current theory is that the spots are composed of fragments of basaltic ash or aggregates of dark dust that would form sublimation residues. Although the European Space Agency (ESA) has not yet formulated a theory, it has indicated that the location and shape of the spots are at odds with a physical explanation.

In 1965, the Mariner 4 probe discovered that the Mars planet does not have a global magnetic field that would protect the planet against the potentially lethal consequences of cosmic radiation and solar radiation, the observations made in the late 1990s by the Mars Global Surveyor probe have confirmed this finding. Scientists surmise that the lack of magnetic protection has allowed the solar wind to blow much of Mars' atmosphere over billions of years.

In 2007, it was calculated that cosmic radiation damage to DNA and RNA has pushed life back to Mars to a depth of at least $7.5 \mathrm{~m}$. As a result, the best hope for a story of life on Mars lies in an environment that has not yet been studied: The basement.

The Phoenix mission was to land a lander in the North Polar Region of Mars on May 25, 2008. It ran until November 10, 2008.

The two main objectives of the mission are to identify in the Martian regolith a "habitable zone" for microbial life and to study the geological history of water on Mars.

The LG is equipped with a robotic arm of $2.5 \mathrm{~m}$ capable of digging a trench of $0.5 \mathrm{~m}$ in the regolith. An electrochemistry experiment analyzes the ions present in the soil and determines in particular the quantity and the type of antioxidants present on Mars. The Viking program data seem to indicate that the abundance of oxidants on Mars may vary with latitude, since Viking 2 found less oxidants than Viking 1, located further south. Phoenix lands him even further north than these two predecessors (Fig. 4).

Preliminary data from Phoenix indicate that Mars soil contains perchlorates and may not be as life-friendly as envisioned. PH and salinity were considered benign from a biological point of view. The analyzers also indicate the presence of bound water and $\mathrm{CO}^{2}$.

The Mars Science Laboratory (MSL) was launched on November 26, 2011 by NASA and was launched on August 6, 2012. It includes instruments and experiments aimed at past or present conditions consistent with biological activity. NASA plans to launch the Astrobiology Field Laboratory in 2016, to help answer the question of life on Mars. The Mars Exploration and Payload Analysis Group is responsible for deciding what the mission's experiences will be.

It has been advocated for future missions sampling at different depths below the surface, where, according to some, liquid water could be found and where microorganisms can survive cosmic radiation.

Mars Sample Return: The best life-detection experience is the examination of a soil sample from Mars on Earth. However, the difficulty of providing and maintaining the supports of life during the months of transit from the planet Mars remains to be solved. Providing the environment and meeting nutritional needs still unknown is a challenge. If life forms are found dead in a sample, it will be difficult to conclude whether these organisms were alive at the outset.

March 2020: Mission expected in 2020, a rover will be sent to Mars to analyze the surface of Mars thanks to the SuperCam project, developed at LAB (Laboratory of Astrophysics of Bordeaux) which will have compared to Curiosity, a green laser and more red laser. Other instruments will be on board such as a sample analyzer, a probe. 
Relly Victoria Virgil Petrescu et al. / American Journal of Engineering and Applied Sciences 2018, 11 (1): 78.91

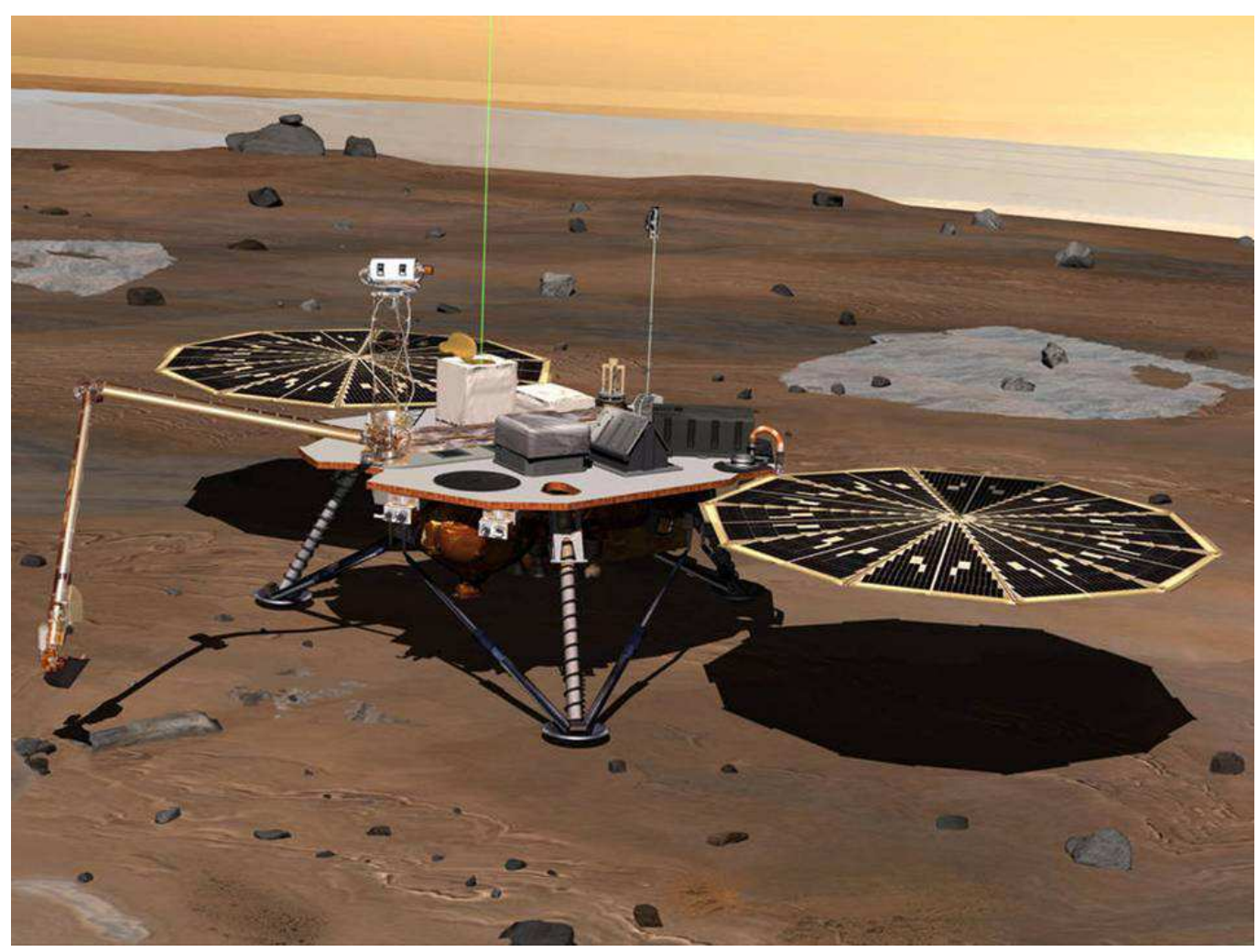

Fig. 4: Phoenix lander (2008)

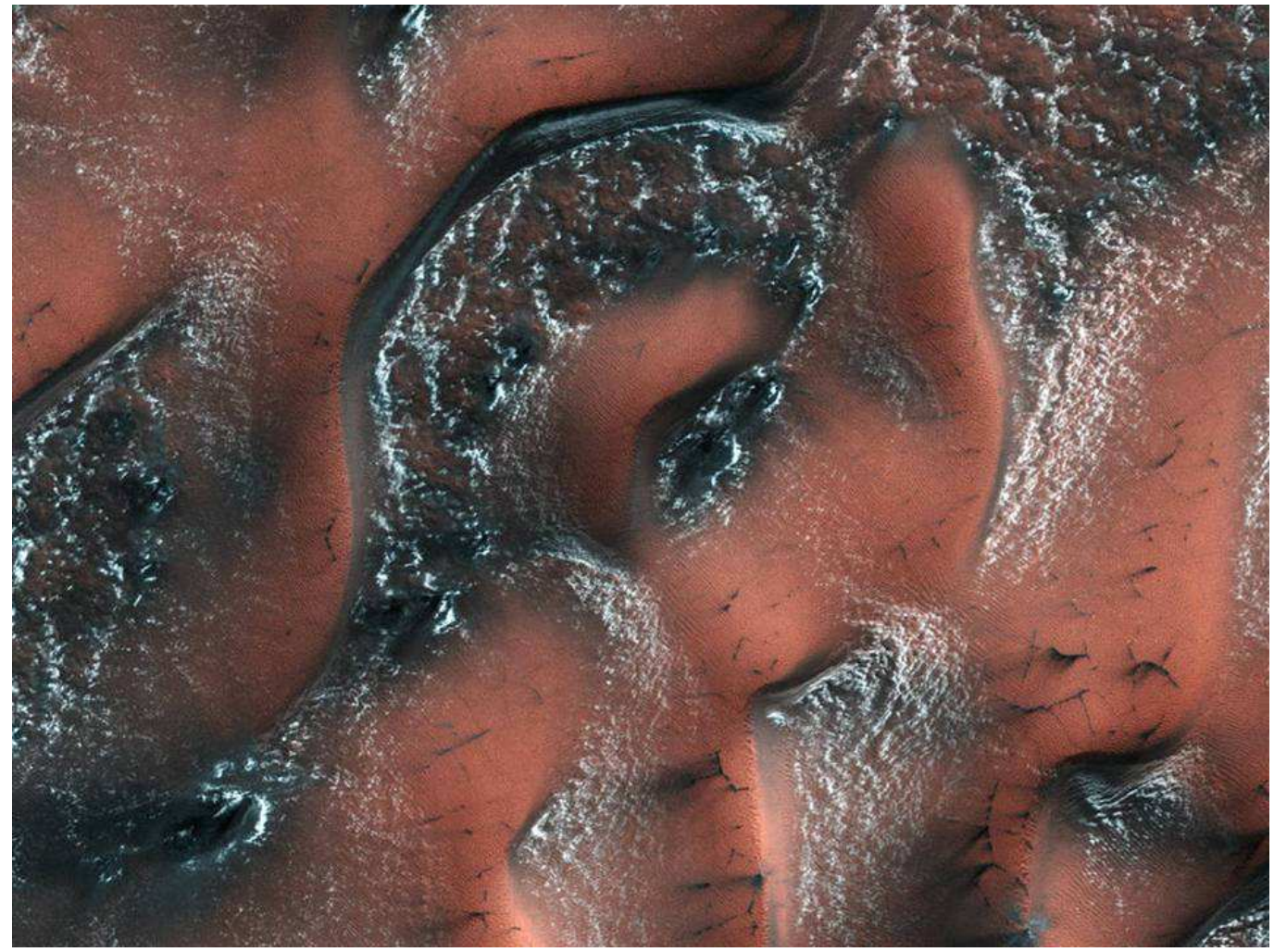

Fig. 5: A World of Snowy dunes on Mars 
This photo of the surface of Mars (Fig. 5), which shows snow-covered sand dunes, was made on May 21, 2017 with the High Resolution Imaging Science Experiment (HiRISE) camera from the Mars Reconnaissance Orbiter orbital probe, belonging to GODMOTHER.

When the photo was taken, it was spring in the northern hemisphere of the Red Planet. In the winter of March, sand dunes were completely covered by snow and ice. Unlike Earth, the snow and ice on Mars is made up of carbon dioxide and not water and is also called "dry ice."

When the sun's rays begin to shy warm the Martian surface during the spring, the ice on the smooth surface of the dunes breaks and the released carbon dioxide pushes sand and darker dust into the dune's surface, producing some beautiful "drawings" visible from orbit. On the less smooth side of the dune, the dry ice lasts longer, being shaded by the edges of the dunes.

\section{Conclusion}

It is possible to live on Mars. For this, however, we need to prepare it properly. The process will be lasting. There is no question of giving up such a vital project for humanity, because Mars is the closest one to us and it already has living conditions similar to those on the earth, but it seems to have lost much of it with some undesirable, perhaps nuclear, events, so that he now lost the defensive magnetic shield and with him and his atmosphere.

All we have to do is start working seriously on restoring living conditions on this neighboring, friendly planet.

This reality of the massive presence at some points of the planet Mars of carbon dioxide snow, can help us enormously in our attempt to reform the red planet to make it live. Hydrogen today can be obtained virtually from any element through a specific nuclear reaction, being basically the chemical element number 1 that has the atom or a single proton. For this reason, it is economically and technically easy to manufacture hydrogen directly on Mars in industrial quantities. Oxygen is more difficult to manufacture and the fact that it already exists on Mars in large quantities in carbon dioxide compounds favors because we can extract it directly out of the carbonic snow. I guess you already guess what we mean. We can produce light hydrogen and extract oxygen from the carbonate, directly on Mars, so we can simply combine them by combustion, simply and get so large quantities of water to rebuild the rivers, lakes and the large red planet, transforming it again on a blue planet.

Here is a serious starting point in our future businesses about conquering Mars.

\section{Acknowledgment}

The work was appreciated by Associate Professor Aniello Riccio Seconda Universita' Degli Studi Di NapolI Italy, Dr. (Ms.) Shweta Agarwala Senior Research Scientist at Singapore Center for 3D Printing Nanyang Technological University Singapore, whom we thanks and in this way.

\section{Author's Contributions}

All the authors contributed equally to prepare, develop and carry out this manuscript.

\section{Ethics}

This article is original. Authors declare that are not ethical issues that may arise after the publication of this manuscript.

\section{References}

Aversa, R., F.I.T. Petrescu, R.V. Petrescu and A. Apicella, 2016a. Biomimetic FEA bone modeling for customized hybrid biological prostheses development. Am. J. Applied Sci., 13: 1060-1067. DOI: 10.3844/ajassp.2016.1060.1067

Aversa, R., D. Parcesepe, R.V. Petrescu, G. Chen and F.I.T. Petrescu et al., 2016b. Glassy amorphous metal injection molded induced morphological defects. Am. J. Applied Sci., 13: 1476-1482.

DOI: 10.3844/ajassp.2016.1476.1482

Aversa, R., R.V. Petrescu, F.I.T. Petrescu and A. Apicella, 2016c. Smart-factory: Optimization and process control of composite centrifuged pipes. Am. J. Applied Sci., 13: 1330-1341.

DOI: 10.3844/ajassp.2016.1330.1341

Aversa, R., F. Tamburrino, R.V. Petrescu, F.I.T. Petrescu and M. Artur et al., 2016d. Biomechanically inspired shape memory effect machines driven by muscle like acting NiTi alloys. Am. J. Applied Sci., 13: 1264-1271.

DOI: 10.3844/ajassp.2016.1264.1271

Aversa, R., R.V.V. Petrescu, A. Apicella and F.I.T. Petrescu, 2017a. Nano-diamond hybrid materials for structural biomedical application. Am. J. Biochemistry Biotechnol.

Aversa, R., R.V. Petrescu, B. Akash, R.B. Bucinell and J.M. Corchado et al., 2017b. Kinematics and forces to a new model forging manipulator. Am. J. Applied Sci., 14: 60-80. DOI: 10.3844/ajassp.2017.60.80

Aversa, R., R.V. Petrescu, A. Apicella, F.I.T. Petrescu and J.K. Calautit et al., 2017c. Something about the $\mathrm{V}$ engines design. Am. J. Applied Sci., 14: 34-52. DOI: 10.3844 /ajassp.2017.34.52 
Aversa, R., D. Parcesepe, R.V.V. Petrescu, F. Berto and G. Chen et al., 2017d. Processability of bulk metallic glasses. Am. J. Applied Sci., 14: 294-301. DOI: 10.3844/ajassp.2017.294.301

Aversa, R., R.V. Petrescu, A. Apicella and F.I. Petrescu, 2017e. Under water. OnLine J. Biol. Sci., 17: 70-87. DOI: $10.3844 /$ ojbsci.2017.70.87

ExoMars, From Wikipedia, the free encyclopedia.

Life on Mars, From Wikipedia, the free encyclopedia.

Mirsayar, M.M., V.A. Joneidi, R.V.V. Petrescu, F.I.T. Petrescu and F. Berto, 2017. Extended MTSN criterion for fracture analysis of soda lime glass. Eng. Fracture Mechan., 178: 50-59.

DOI: 10.1016/j.engfracmech.2017.04.018

Petrescu, F.I.T., 2009. New aircraft. Proceedings of the 3rd International Conference on Computational Mechanics, Oct. 29-30, Brasov, Romania.

Petrescu, F.I.T., 2012a. Cold Nuclear Fusion. 1st Edn., Create Space, USA, ISBN-13: 1478234261, pp: 80.

Petrescu, F.I.T., 2012b. Particle Annihilation-a source of renewable energy?

Petrescu, F.I.T. and J.K. Calautit, 2016a. About nano fusion and dynamic fusion. Am. J. Applied Sci., 13: 261-266. DOI: 10.3844/ajassp.2016.261.266

Petrescu, F.I. and J.K. Calautit, 2016b. About the light dimensions. Am. J. Applied Sci., 13: 321-325. DOI: 10.3844/ajassp.2016.321.325

Petrescu, F.I. and R.V. Petrescu, 2011a. Memories about Flight. 1st Edn., CreateSpace, pp: 652.

Petrescu, F.I. and R.V. Petrescu, 2011b. Mechanical Systems, Serial and Parallel - Course. 1st Edn., LULU Publisher, London, UK, ISBN-13: 978-1-4466-0039-9, pp: 124.

Petrescu, R.V. and F.I.T. Petrescu, 2012a. Northrop. 1st Edn., Books on Demand, ISBN-13: 978-3848209323, pp: 142.

Petrescu, F.I. and R.V. Petrescu, 2012b. New Aircraft II. 1 st Edn., Books on Demand, pp: 138.

Petrescu, F.I. and R.V. Petrescu, 2012c. MecatronicaSisteme Seriale Si Paralele. 1st Edn., Create Space Publisher, USA, ISBN-10: 978-1-4750-6613-5, pp: 128.

Petrescu, F.I. and R.V. Petrescu, 2012d. Kinematics of the planar quadrilateral mechanism. Engevista, 14: 345-348.

Petrescu, R.V. and F.I. Petrescu, 2013a. Lockheed Martin. 1st Edn., CreateSpace, pp: 114.

Petrescu, R.V. and F.I. Petrescu, 2013b. Northrop. 1st Edn., CreateSpace, pp: 96.

Petrescu, R.V. and F.I. Petrescu, 2013c. The Aviation History or New Aircraft I Color. 1st Edn., CreateSpace, pp: 292.

Petrescu, F.I. and R.V. Petrescu, 2013d. Cinematics of the 3R Dyad. Engevista, 15: 118-124.

Petrescu, F.I.T., 2016. Valorificarea Traditiei Ingineresti Romanesti-I. 1st Edn., Create Space Publisher, USA, ISBN-13: 9781537177984.
Petrescu, F.I. and R.V. Petrescu, 2016a. Parallel moving mechanical systems kinematics. Engevista, 18: 455-491.

Petrescu, F.I. and R.V. Petrescu, 2016b. Direct and inverse kinematics to the anthropomorphic robots. Engevista, 18: 109-124.

Petrescu, F.I. and R.V. Petrescu, 2016c. Dynamic cinematic to a structure 2R. Revista Geintec-Gestao. Inovacao E Tecnol., 6: 3143-3154.

Petrescu, R.V.V., R. Aversa, A. Apicella, F. Berto and S. Li et al., 2016a. Ecosphere protection through green energy. Am. J. Applied Sci., 13: 1027-1032. DOI: 10.3844/ajassp.2016.1027.1032

Petrescu, F.I.T., A. Apicella, R.V.V. Petrescu, S.P. Kozaitis and R.B. Bucinell et al., 2016b. Environmental protection through nuclear energy. Am. J. Applied Sci., 13: 941-946. DOI: 10.3844/ajassp.2016.1027.1032

Petrescu, R.V., R. Aversa, B. Akash, J. Corchado and F. Berto et al., 2017a. About northrop grumman. J. Aircraft Spacecraft Technol., 1: 162-185. DOI: $10.3844 /$ jastsp.2017.162.185

Petrescu, R.V., R. Aversa, B. Akash, J. Corchado and F. Berto et al., 2017b. Some special aircraft. J. Aircraft Spacecraft Technol., 1: 186-203. DOI: $10.3844 /$ jastsp.2017.186.203

Petrescu, R.V., R. Aversa, B. Akash, J. Corchado and F. Berto et al., 2017c. When boeing is dreaming - a review. J. Aircraft Spacecraft Technol., 1: 149-161. DOI: 10.3844 /jastsp.2017.149.161

Petrescu, R.V., R. Aversa, B. Akash, J. Corchado and F. Berto et al., 2017d. Airlander. J. Aircraft Spacecraft Technol., 1: 119-148. DOI: $10.3844 /$ jastsp.2017.119.148

Petrescu, R.V., R. Aversa, B. Akash, J. Corchado and F. Berto et al., 2017e. Home at airbus. J. Aircraft Spacecraft Technol., 1: 97-118. DOI: $10.3844 /$ jastsp.2017.97.118

Petrescu, R.V., R. Aversa, B. Akash, J. Corchado and F. Berto, 2017f. About bell helicopter FCX-001 concept aircraft - a short review. J. Aircraft Technol., 1: 91-96. DOI: 10.3844/jastsp.2017.91.96

Petrescu, R.V., R. Aversa, B. Akash, J. Corchado F. Berto et al., 2017g. What is a UFO? J. Aircraft Spacecraft Technol., 1: 1-11. DOI: 10.3844 jastsp.2017.1.8

Petrescu, R.V., R. Aversa, B. Akash, R. Bucinell and J. Corchado et al., 2017h. History of aviation - a short review. J. Aircraft Spacecraft Technol., 1: 30-49. DOI: 10.3844 /jastsp.2017.30.49

Petrescu, R.V., R. Aversa, B. Akash, J. Corchado and F. Berto et al., 2017i. Our universe. J. Aircraft Spacecraft Technol., 1: 69-79. DOI: 10.3844 jastsp.2017.69.79

Petrescu, R.V., R. Aversa, B. Akash, R. Bucinell and J. Corchado et al., 2017j. Lockheed martin - a short review. J. Aircraft Spacecraft Technol., 1: 50-68. DOI: $10.3844 /$ jastsp.2017.50.68 
Petrescu, R.V., R. Aversa, B. Akash, R. Bucinell and J. Corchado et al., 2017k. Modern propulsions for aerospace-part II. J. Aircraft Spacecraft Technol., 1: 9-17. DOI: 10.3844/jastsp.2017.9.17

Petrescu, R.V., R. Aversa, B. Akash, R. Bucinell and J. Corchado et al., 20171. Modern propulsions for aerospace-a review. J. Aircraft Spacecraft Technol., 1: 1-8. DOI: 10.3844/jastsp.2017.1.8

Petrescu, R.V., R. Aversa, B. Akash, J. Corchado and F. Berto et al., $2017 \mathrm{~m}$. About helicopters. J. Aircraft Spacecraft Technol., 1: 204-223. DOI: $10.3844 /$ jastsp.2017.204.223

Petrescu, R.V., R. Aversa, B. Akash, F. Berto and A. Apicella et al., 2017n. The modern flight. J. Aircraft Spacecraft Technol.

Petrescu, R.V., R. Aversa, B. Akash, F. Berto and A. Apicella et al., 2017o. Sustainable energy for aerospace vessels. J. Aircraft Spacecraft Technol.

Petrescu, R.V., R. Aversa, B. Akash, F. Berto and A. Apicella et al., 2017p. Unmanned helicopters. J. Aircraft Spacecraft Technol.

Petrescu, R.V., R. Aversa, B. Akash, F. Berto and A. Apicella et al., 2017q. Project HARP. J. Aircraft Spacecraft Technol.
Tosca, N.J., A.H. Knoll and S.M. McLennan, 2008. Water activity and the challenge for life on early Mars. Science, 320: 1204-1207.

DOI: $10.1126 /$ science. 1155432

\section{Source of Figures}

\section{Fig. 1:}

https://en.wikipedia.org/wiki/ExoMars\#/media/File:Cmg lee_Cambridge_Science_Festival_2015_ExoMars_Rove r.jpg

Fig. 2:

https://en.wikipedia.org/wiki/ExoMars\#/media/File:Ober hausen_-_Gasometer_-_Sternstunden_33_ies.jpg

Fig. 3:

https://en.wikipedia.org/wiki/Life_on_Mars\#/media/File: PIA19673-Mars-AlgaCrater-ImpactGlassDetectedMRO-20150608.jpg

Fig. 4:

https://www.nasa.gov/multimedia/imagegallery/image_f eature_857.html 